\title{
Outcomes of anterior myotomy versus posterior myotomy during POEM: a randomized pilot study
}

\section{다 (1) $\odot$}

\author{
Authors \\ Mohan Ramchandani, Zaheer Nabi, D. Nageshwar Reddy, Rahul Talele, Santosh Darisetty, Rama Kotla, Radhika \\ Chavan, Manu Tandan
}

Institution

Department of Medical Gastroenterology, Asian Institute of Gastroenterology, Hyderabad, India

submitted 20.4.2017

accepted after revision 25.9.2017

Bibliography

DOI https://doi.org/10.1055/s-0043-121877 |

Endoscopy International Open 2018; 06: E190-E198

(c) Georg Thieme Verlag KG Stuttgart · New York

ISSN 2364-3722

Corresponding author

Mohan Ramchandani, Asian Institute of Gastroenterology,

6-3-661, Somajiguda, Hyderabad 500 082, India

Fax: +91-40 23324255

ramchandanimohan@gmail.com

\section{ABSTRACT}

Background and study aims Peroral endoscopic myotomy (POEM) can be performed via an anterior or posterior approach, depending on the operator's preference. Data are lacking on comparative outcomes of both approaches.

Patients and methods This is a pilot randomized study comparing endoscopic anterior and posterior myotomy during POEM in patients with Achalasia cardia (AC). Patients were randomized into 2 groups ( $\mathrm{n}=30$ in each group); anterior myotomy group (AG) and posterior myotomy group (PG) and were followed at 1, 3 and 6 months after POEM.

Results Technical success was achieved in $100 \%$ of cases in both groups and total operative time was comparable (AG $65 \pm 17.65$ minutes versus PG $-61.2 \pm 16.67 ; P=0.38$ ); Mucosotomies were more frequent in AG ( $20 \%$ vs $3.3 \%$; $P=$ 0.02 ). Difference in other perioperative adverse events $(A E)$ including insufflation-related $A E$ and bleeding in both groups were statistically insignificant. At 1-month followup Eckardt score AG $0.57 \pm 0.56$ vs PG $0.53 \pm 0.71$; $(P=$ 0.81 ), mean LES pressure AG $11.93 \pm 6.36$ vs PG $11.77 \pm$ $6.61 ;(P=0.59)$ and esophageal emptying on timed barium swallow at 5 minutes AG $1.32 \pm 1.08 \mathrm{~cm}$ vs PG $1.29 \pm$ $0.79 \mathrm{~cm}$; $(P=0.09)$ were comparable in both groups. At 3 months, Eckardt score $(0.52 \pm 0.59$ vs $0.63 \pm 0.62 ; P=0.51)$ was similar in both groups. Incidence of esophagitis on EGD was comparable in both groups (24\% vs $33.3 \%$; $P=$ $0.45)$, however, $\mathrm{pH}$ metry at 3 months showed significantly more esophageal acid exposure in posterior group $(2.98 \% \pm$ 4.24 vs $13.99 \% \pm 14.48$; $P<0.01)$. At 6 months clinical efficacy and LES pressures were comparable in both groups. Conclusion Anterior and posterior approaches to POEM seem to have equal efficacy. However, the occurrence of mucosotomies was higher in the anterior myotomy group and acid exposure was higher with the posterior myotomy approach during POEM.

\section{Introduction}

Achalasia cardia $(A C)$ is a neurodegenerative disorder of the esophagus characterized by insufficient lower esophageal sphincter (LES) relaxation and esophageal aperistalsis. Treatment options which are available for these patients include medical management, pneumatic balloon dilatation (PBD), laparoscopic Heller's myotomy (LHM), Botulinum toxin injection (BTI), per oral endoscopic myotomy (POEM) and esophagectomy. Graded PBD and LHM with partial fundoplication are equally effective as first-line treatment for patients with type I and type II AC, whereas type III AC responds better to LHM [1].
POEM is a minimally invasive technique with equal efficacy, safety and shorter hospital stay when compared to LHM [2].

POEM has emerged as the new endoscopic treatment for AC at many centers. Since its initial description, the technique and devices have been evolving to make the POEM procedure easier, safer and more effective [3]. However, being a relatively new innovation, the operative technique is yet to be standardized.

The major technical variation in POEM has been the orientation of myotomy. Anterior myotomy involves cutting muscle fibers in the 1 to 2 o'clock position ( $\mathbf{F i g . 1}$ ), whereas muscle fibers are cut in the 5 o'clock direction ( $\triangleright$ Fig. 2 ) with the posterior approach. The choice of myotomy approach is largely de- 

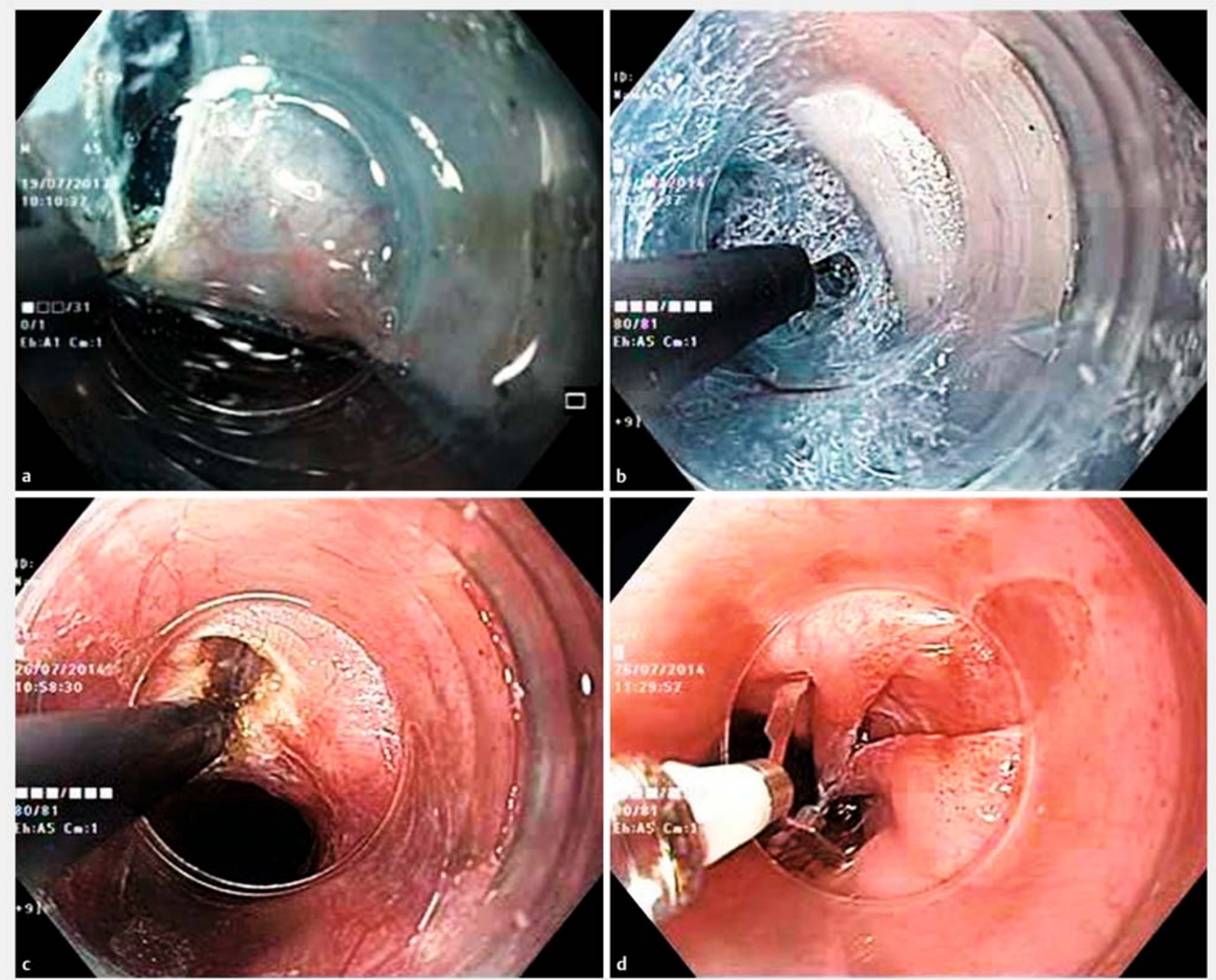

- Fig. 1 Peroral endoscopic myotomy (anterior approach). a Mucosal incision at 1 to 2 o'clock position. b Submucosal dissection. c Myotomy. d Closure of mucosal incision.

pendent on the operator's preference and the pertinent clinical situation. However, there are no randomized studies comparing these 2 approaches and differences in outcomes between the 2 approaches are not known. The efficacy of both anterior and posterior approaches appears to be equal in previous studies [4]. However, these studies were conducted at different centers, and direct comparison may not be appropriate. Hence, we conducted a randomized controlled trial with the aim of comparing the efficacy and adverse events encountered with two techniques.

\section{Patients and methods}

The study was conducted at a single tertiary care center (Asian Institute of Gastroenterology) after obtaining approval from the institutional review board. The study protocol was also registered with Clinical Trials Registry of India (CTRI), which is a primary registry of WHO Registry Network (CTRI/2016/05/
006949). All authors had access to the study data and reviewed and approved the final manuscript.

Primary outcome measures:

1. Comparison of changes in the Eckardt score

2. Comparison of operative details and perioperative adverse events

Secondary outcome measures:

1. Changes in LES pressures by manometry.

2. Change in barium column height on barium esophagogram.

3. Comparison of symptoms of GERD post POEM by GERD FSSG questionnaire.

4. Twenty-four-hour pH monitoring and comparison of reflux rates and DeMeester score.

5. Esophagogastroduodenoscopy to assess changes of GERD. 

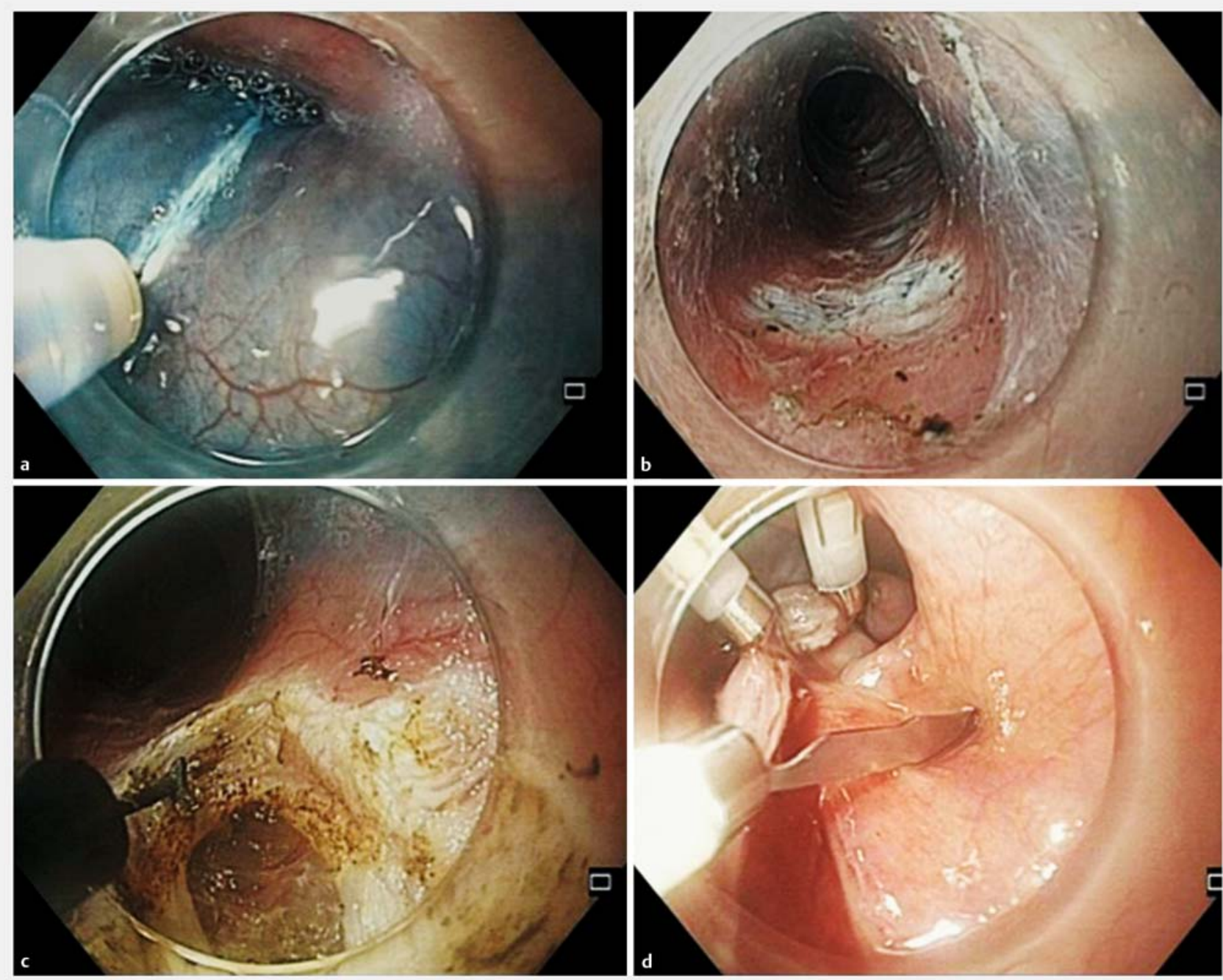

- Fig. 2 Peroral endoscopic myotomy (posterior approach). a Mucosal incision at 5 o'clock position. b Submucosal dissection. c Myotomy. d Closure of mucosal incision.

\section{Study design}

This was a blinded (Participant and Outcome Assessor Blinded), randomized controlled trial.

Consecutive eligible patients with symptomatic primary AC who were admitted at Asian Institute of Gastroenterology, Hyderabad, from August 2015 to April 2016 were enrolled into the study. Patients undergoing POEM were randomized in 2 groups [those with anterior myotomy (anterior group; AG) and those with posterior myotomy (posterior group; PG)] in 1:1 ratio, according to the computer-generated algorithm (Random Allocation Software v2.0).

\section{Sample size calculation and statistical analysis}

This study was intended as a pilot study. Hypothesizing a difference of $5 \%$ in the efficacy of the POEM using posterior approach compared to anterior approach and two sided $\alpha$ value of 0.05 with $80 \%$ power $(1-\beta)$, estimated sample size for a RCT was 341 patients in each anterior and posterior arm. This being a pilot study, $10 \%$ of the original sample size was enrolled to assess the hypothesis. Data were prospectively collected, and comparison of pre- and post-procedure parameters was done. Student's paired $t$-test was used for continuous variables and proportion test for categorical variables. Subgroup analysis was done. The data were analyzed using Statistical Package for Social sciences (SPSS $21^{\text {st }}$ version). A $P$ value $<0.05$ was considered significant.

The inclusion criterion for the study was primary achalasia cardia with Eckardt score $>3$ and no history of previous endoscopic or surgical myotomy. Exclusion criterion included active severe esophagitis, large $(>3 \mathrm{~cm})$ hiatal hernia, sigmoid esophagus (distal esophagus diameter $>10 \mathrm{~cm}$ ) and hematological, cardiac, pulmonary comorbidities or other contraindications to endoscopy. All patients were counselled about the procedure and written informed consent was obtained. 


\section{Operator experience}

POEM has been performed at this center since 2013 and the experience now includes more than 500 cases. All 3 operators (DNR, MR, ZN) have adequate expertise with POEM using both anterior myotomy and posterior myotomy approaches.

\section{Preoperative assessment}

Patients from both groups underwent preoperative assessment, which included:

1. Standardized validated symptom assessment and grading of AC according to Eckardt score

2. High-resolution esophageal manometry (HRM) - for diagnosis and classification of AC

3. Esophagogastroduodenoscopy (EGD)

4. Timed barium swallow (TBS)

\section{Intraoperative assessment}

Operative details including total time required for POEM, time required for tunneling, myotomy, closure with clips, length of myotomy, number of clips required to close the mucosal incision and intraoperative adverse events (AEs) were noted.

\section{Postoperative assessment}

Patients from both groups were observed for any immediate postoperative complications. All patients were scheduled for follow-up visits at 1, 3 and 6 months. All patients underwent physical examination, Eckardt score calculation, TBS and HRM at 1-month follow-up visit. Patients underwent physical examination, Eckardt score calculation, and FSSG (frequency scale symptom of gastroesophageal reflux) assessment, EGD and 24-hour pH monitoring 3 months after POEM. Patients underwent physical examination, Eckard score calculation and HRM at the 6-month follow-up visit.

\section{POEM technique}

Patients were placed on a clear liquid diet for 24 hours before the procedure. Prophylactic antibiotic (Pipracillin Tazobactam $4.5 \mathrm{~g}$ ) was given 30 minutes before the procedure and continued for the next 3 to 7 days. POEM was performed according to the standard procedure, which involved mucosal incision, submucosal tunneling, myotomy and closure using clips [5, 6]. The approach to myotomy was decided according to the randomization protocol - either anterior (1-2 o'clock position) or posterior (5 o'clock position).

\section{Investigations methodology}

\section{Timed barium swallow}

TBS included upright spot films obtained at 1,2 and 5 minutes after ingestion of $100 \mathrm{~mL}$ to $150 \mathrm{~mL}$ of low-density ( $45 \%$ weight in volume) barium sulfate [7]. Comparison of esophageal emptying before and after POEM was done in each arm at 1 month. The height of barium column was calculated to quantify an estimate of esophageal emptying.

\section{Esophageal manometry}

HRM was carried out with a 16-channel water-perfused catheter that has 8 channels $1-\mathrm{cm}$ apart at the lower end and the remaining 8 channels $3-\mathrm{cm}$ apart (Dentsleeve International Pty Ltd; Mui Scientific, Ontario, Canada). Data was analyzed using Trace 1.2V software (Geoff Hebbard, Royal Melbourne Hospital, Victoria, Australia). Patients were classified into achalasia subtypes according to the Chicago classification of esophageal motility disorders (V 3.0) [8].

\section{Evaluation of gastroesophageal reflux (GERD)}

Patients were evaluated for GERD by clinical history; EGD and 24-hourspH metry at 3-month follow-up. A validated GERD questionnaire form (FSSG) was used for diagnosis of GERD [9]. A score of more than 8 points suggested presence of GERD.

\section{Twenty-four-hour pH monitoring}

Twenty-four-hour $\mathrm{pH}$ monitoring was performed in all patients 3 months after POEM. Patients were asked to stop proton pump inhibitors (PPI) 5 days before the proposed date of test. The procedure was performed as per standard protocol. The $\mathrm{pH}$ probe was placed transnasally, which was connected to a $\mathrm{pH}$ data acquisition device (ZepHr pH monitor with ComforTEC disposable catheters, Sandhill Scientific, Highlands Ranch, CO, USA) [10]. Total number of reflux episodes, acid exposure time and composite DeMeester Score were measured. A DeMeester score > 14.7 was considered as indicative of GERD.

\section{Results}

\section{Patient characteristics}

Sixty eligible patients with AC were randomized into 2 groups ( Fig.3), with 30 patients in each group.

Patients in both groups had comparable demographic characteristics as shown in $>$ Table 1 . Mean age of patients, duration of illness, sex distribution and baseline Eckardt Score were comparable in both groups. The majority of patients (70\%) had type II AC. Patients in both groups had comparable mean LES pressure and Integrated relaxation pressures (IRP) on manometry.

\section{Operative details}

All cases were completed successfully, which indicates $100 \%$ technical success in both the arms ( $\triangleright$ Table 2 ). Operative details were compared in both groups. Total time required was less in the posterior group, however, the difference was not statistically significant $(61.2 \pm 16.67 \mathrm{~min}$ in $\mathrm{PG}$ vs. $65 \pm 17.65 \mathrm{~min}$ in AG; $P=0.38$ ). In further analysis, time required for closure of mucosal incision (clipping) in the PG was significantly less than in AG (AG $8.15 \pm 4.01 \mathrm{~min}$ vs. $6.46 \pm 2.44 \mathrm{~min}$ in $P G$; $P=0.04$ ). The average length of myotomy was similar in both groups.

$P G$ required fewer clips to close the mucosal entry site (AG $6.27 \pm 1.73$ vs. $4.87 \pm 1.09$ in $P G ; P=<0.01)$.

There was no significant difference between frequency of insufflation-related AEs requiring decompression like pneumoperitoneum and pneumothorax ( $\vee$ Table 2 ). 


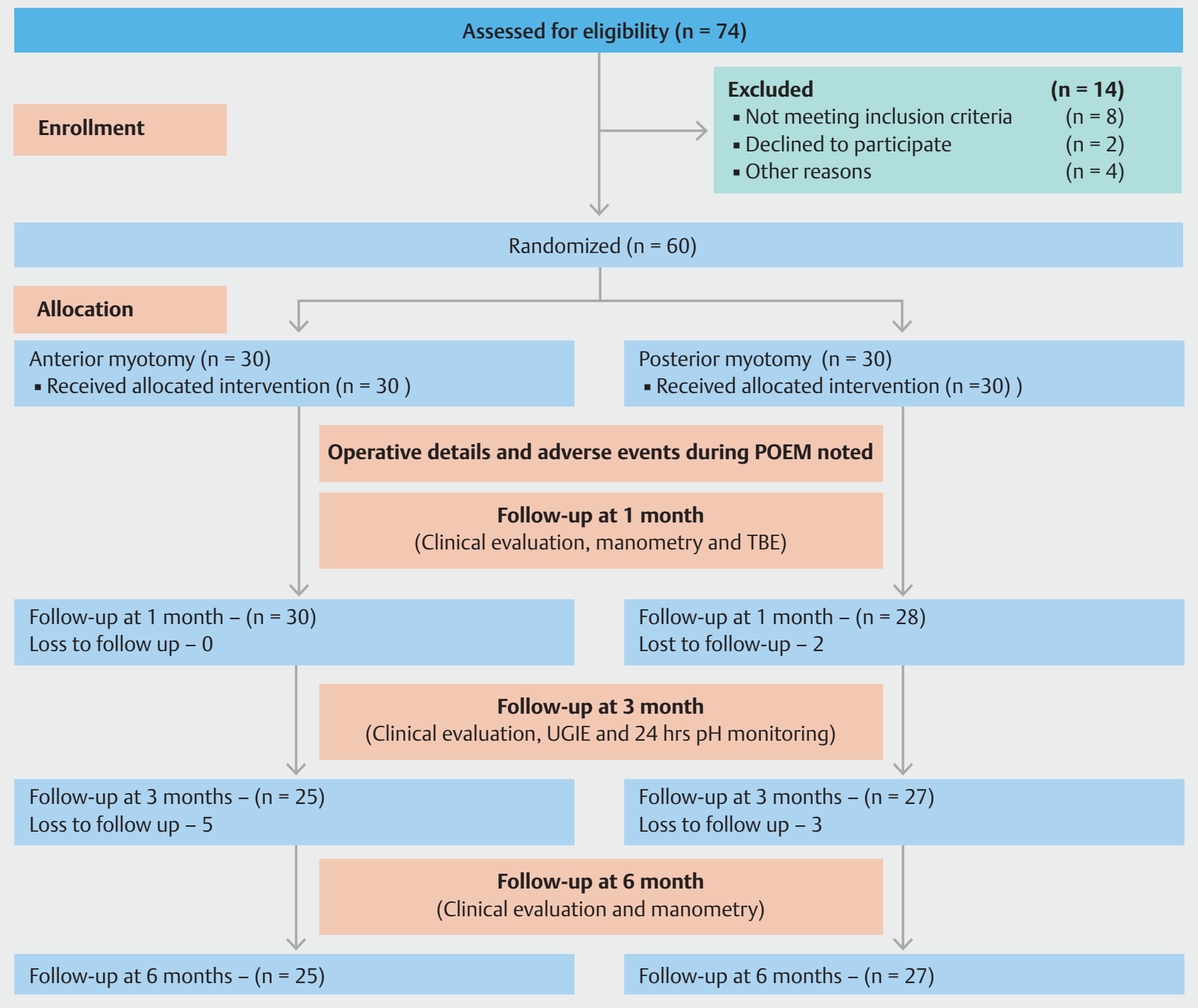

\section{Analysis}

- Fig. 3 Consort diagram.

Clinically significant pneumoperitoneum was noted in 11 patients $(36.66 \%)$ in the anterior group and 7 patients $(23.33 \%)$ in the posterior group. Pneumothorax was noted in 3 patients $(10 \%)$ in the anterior group and 2 patients $(6.66 \%)$ in the posterior group. All patients were managed conservatively. No evidence of any major bleed was noted in either group. The number of minor bleeds requiring hemostasis with coagulation forceps was similar in both groups. Mucosal perforation was noted in 6 patients $(20 \%)$ during POEM in anterior myotomy as compared to 1 patient (3.33\%) in the posterior myotomy group $(P=0.03)$.

Mean hospital stay was similar for both groups (AG $-4.06 \pm$ 0.24 vs. $4.31 \pm 0.82$ days in $P G ; P=0.09$ )
Treatment response was assessed with several metrics including symptom assessment, decrease in LES pressure and improvement in esophageal emptying as assessed by TBS.

\section{Follow-up at 1 month}

At 1-month follow-up, patients in both groups showed significant reduction in Eckardt scores as compared to the pre-POEM levels. At 1 month after POEM, mean Eckardt Score in AG was $0.57 \pm 0.5$ as compared to mean score of $0.53 \pm 0.71$ in the PG $(P=0.81)$.

There was significant reduction in LES pressures and mean IRP in both groups after the POEM procedure.

Esophageal emptying was assessed using TBS. Improvement in height of barium column in the TBE was observed and was comparable in both groups after POEM ( $>$ Table 3 ). Both 


\begin{tabular}{|c|c|c|c|c|}
\hline & & $\begin{array}{l}\text { Anterior } \\
\text { myotomy }\end{array}$ & $\begin{array}{l}\text { Posterior } \\
\text { myotomy }\end{array}$ & $P$ value \\
\hline \multicolumn{2}{|c|}{ Number of patients (n) } & 30 & 30 & \\
\hline \multicolumn{2}{|c|}{$\begin{array}{l}\text { Age in years } \\
(\text { mean } \pm S D)\end{array}$} & $38 \pm 13.35$ & $43.9 \pm 15.7$ & 0.11 \\
\hline \multirow[t]{2}{*}{ Sex } & Male & 15 & 18 & \multirow[t]{2}{*}{0.58} \\
\hline & Female & 15 & 12 & \\
\hline \multicolumn{2}{|c|}{$\begin{array}{l}\text { Duration of illness } \\
\text { (months) }\end{array}$} & $22.2 \pm 28.1$ & $35.6 \pm 37.6$ & 0.17 \\
\hline \multicolumn{2}{|c|}{ Eckardt Score } & $7.3 \pm 1.3$ & $7.03 \pm 1.1$ & 0.37 \\
\hline \multicolumn{5}{|c|}{ Achalasia subtypes } \\
\hline \multicolumn{2}{|c|}{ Type I } & 5 & 6 & 0.73 \\
\hline \multicolumn{2}{|c|}{ Type II } & 21 & 21 & 1.00 \\
\hline \multicolumn{2}{|c|}{ Type III } & 4 & 3 & 0.68 \\
\hline \multicolumn{2}{|c|}{ Post PBD } & 7 & 10 & 0.38 \\
\hline \multicolumn{2}{|c|}{ Post BTI } & 0 & 1 & 0.31 \\
\hline \multicolumn{5}{|c|}{ Manometry } \\
\hline \multicolumn{2}{|c|}{$\begin{array}{l}\text { LES pressure } \\
(\text { mean } \pm \mathrm{SD} \text { mmHg) }\end{array}$} & $38.7 \pm 16.18$ & $34.2 \pm 17.55$ & 0.28 \\
\hline \multicolumn{2}{|c|}{ IRP $($ mean \pm SD mmHg $)$} & $27.19 \pm 15.8$ & $18.5 \pm 14.1$ & 0.21 \\
\hline \multicolumn{5}{|c|}{ Timed barium esophagogram (TBE) (Height of barium column in cm) } \\
\hline \multicolumn{2}{|c|}{$1 \mathrm{~min}$} & $16.94 \pm 5.03$ & $15.06 \pm 4.79$ & 0.12 \\
\hline \multicolumn{2}{|c|}{$2 \mathrm{~min}$} & $13.19 \pm 4.1$ & $11.81 \pm 4.69$ & 0.21 \\
\hline \multicolumn{2}{|c|}{$5 \mathrm{~min}$} & $11.25 \pm 3.63$ & $9.76 \pm 4.65$ & 0.15 \\
\hline \multicolumn{5}{|c|}{ Number of cases by each operator } \\
\hline \multicolumn{2}{|c|}{ Operator 1} & 10 & 14 & 0.28 \\
\hline \multicolumn{2}{|c|}{ Operator 2} & 9 & 10 & 0.78 \\
\hline \multicolumn{2}{|c|}{ Operator 3} & 11 & 6 & 0.15 \\
\hline
\end{tabular}

groups showed significant reduction in height of the barium column at 1 -month follow-up.

\section{Follow-up at 3 months}

Patients in both groups maintained the comparable symptomatic improvement achieved at 1 month. Post-POEM, both groups had similar FSSG scores without any statistically significant difference $(5.46 \pm 4.12$ in $A G$ vs. $5.93 \pm 3.00$ in $P G ; P=$ $0.63)$.

Twenty-four-hour pH monitoring showed total acid exposure and DeMeester scores were significantly higher in the posterior group. EGD revealed evidence of esophagitis in 6 (24\%) patients in the anterior group and $9(33.3 \%)$ patients in the posterior group $(P=0.45)$. 
Table 3 Assessment of efficacy at 1-month follow-up.

\begin{tabular}{|l|c|c|c|}
\hline Parameter & Anterior group & \multicolumn{1}{l|}{$\begin{array}{l}\text { Posterior } \\
\text { group }\end{array}$} & P value \\
\hline Eckardt score & $0.57 \pm 0.56$ & $0.53 \pm 0.71$ & 0.81 \\
\hline LES pressures $(\mathbf{m m H g})$ & & \\
\hline Mean & $11.93 \pm 6.36$ & $11.77 \pm 6.61$ & 0.59 \\
\hline Max & $16.25 \pm 8.98$ & $14.61 \pm 8.76$ & 0.48 \\
\hline Min & $8.53 \pm 5.21$ & $8.14 \pm 5.62$ & 0.88 \\
\hline IRP & & & \\
\hline Mean & $5.88 \pm 5.33$ & $7.26 \pm 6.49$ & 0.38 \\
\hline Max & $7.12 \pm 6.82$ & $8.08 \pm 8.34$ & 0.62 \\
\hline Min & $4.36 \pm 4.49$ & $4.94 \pm 5.07$ & 0.51 \\
\hline TBE (height in cm) & & & \\
\hline 1 min & $6.65 \pm 2.94$ & $7.45 \pm 2.16$ & 0.23 \\
\hline 2 min & $2.75 \pm 1.68$ & $2.41 \pm 2.13$ & 0.50 \\
\hline 5 min & $1.32 \pm 1.08$ & $1.29 \pm 0.79$ & 0.09 \\
\hline & & & \\
\hline
\end{tabular}

relevant differences in outcomes is largely speculative based on expert observations $[15,18]$.

In this randomized controlled pilot trial, we observed that both anterior and posterior myotomy in POEM procedure have similar operative times, but different mucosotomy and GERD rates. Posterior myotomy was associated with a higher occurrence of GERD, whereas the anterior approach was associated with a higher incidence of mucosal injury.

POEM was successfully completed in all the 60 patients (30 patients in each arm). POEM can be performed with either approach with similar technical success. In our study, all 3 operators had already completed their learning curve, as defined in previous studies [19].

Clinical efficacy of POEM measured by improvement in Eckardt Scores, reduction of LES pressure and height of barium column in TBS were equivalent in both groups. These results are consistent with previous studies, in which POEM has been found to be effective with either approach [3, 20,21].

Procedure duration was comparable in the posterior and anterior myotomy groups (anterior-65 min versus posterior$61.2 \mathrm{~min} ; P=0.38$ ). In our study, mucosal incision closure was significantly faster with the posterior approach (posterior$6.46 \pm 2.44$ mins vs anterior $-8.15 \pm 4.01$ mins; $P=0.04$ ). Significantly fewer clips were required for closure in the posterior group and therefore, closure is quicker in that group. In contrast to incision closure time, there was no significant differ-

Table 4 Evaluation at 3-month follow-up post-POEM.

\begin{tabular}{|c|c|c|c|}
\hline Parameter & Anterior group $(\mathrm{n}=\mathbf{2 5})$ & Posterior group $(n=27)$ & $P$ value \\
\hline Eckardt score & $0.52 \pm 0.59$ & $0.63 \pm 0.62$ & 0.51 \\
\hline \multicolumn{4}{|l|}{ Symptoms of GERD } \\
\hline FSSG questionnaire post-POEM & $5.46 \pm 4.12$ & $5.93 \pm 3.00$ & 0.63 \\
\hline \multicolumn{4}{|l|}{ Esophagogastroduodenoscopy } \\
\hline Normal & $19(76.0 \%)$ & $18(66.7 \%)$ & 0.45 \\
\hline Grade A esophagitis & $4(16.0 \%)$ & $5(18.51 \%)$ & 0.40 \\
\hline Grade B esophagitis & $1(4.0 \%)$ & $2(7.4 \%)$ & 0.29 \\
\hline Grade C esophagitis & 0 & $1(3.7 \%)$ & 0.16 \\
\hline Grade D esophagitis & $1(4.0 \%)$ & $1(3.7 \%)$ & 0.47 \\
\hline \multicolumn{4}{|l|}{ 24-hour Ph monitoring } \\
\hline Total number reflux episodes & $57.28 \pm 36.04$ & $64.2 \pm 46.17$ & 0.54 \\
\hline Total esophageal acid exposure (\%) & $2.98 \pm 4.24$ & $13.99 \pm 14.483$ & $<0.01$ \\
\hline DeMeester score & $9.56 \pm 9.48$ & $35.3 \pm 41.4$ & 0.04 \\
\hline Number of patients with DeMeester score $>14.7$ & $4 / 25(16.0 \%)$ & $10 / 27(37.03 \%)$ & 0.04 \\
\hline \multicolumn{4}{|l|}{ Follow-up at 6 months } \\
\hline & Anterior group & Posterior group & $P$ value \\
\hline LES pressure (mean $\pm \mathrm{SD}$ in $\mathrm{mmHg}$ ) & $13.82 \pm 5.30$ & $11.68 \pm 4.87$ & 0.13 \\
\hline $\operatorname{IRP}($ mean $\pm S D$ in $\mathrm{mmHg})$ & $7.6 \pm 6.48$ & $6.12 \pm 5.50$ & 0.38 \\
\hline Eckardt score & $0.68 \pm 0.62$ & $0.51 \pm 0.58$ & 0.28 \\
\hline
\end{tabular}


ence in the time taken for submucosal tunneling and myotomy. In a retrospective study, comparing anterior versus posterior myotomy, operative time was significantly less with posterior POEM (97 min Anterior, 79 min posterior; $P<0.01$ ). Similar to the results in our study, closure time was faster in the posterior myotomy group (9.6 min Anterior, 7.9 min Posterior; $P=0.02$ ). However, all the procedures were performed by a single operator and the impact of the learning curve was not taken into consideration [20].

AEs commonly associated with POEM include insufflationrelated problems, bleeding (intraprocedural or delayed) and mucosal perforations [4, 21, 22].

Insufflation-related AEs were no different with the two approaches. During POEM there is communication of submucosal tunnel gas with mediastinum and peritoneum. Therefore, insufflation-related events are not uncommon. It is obvious that these events would increase in proportion to the time taken for the procedure [23] and with more operator experience, incidence of these particular AEs should come down.

Minor bleeding occurs commonly during POEM and is controlled using hemostatic forceps or knife with coagulating current. Bleeding can occur at any point during tunneling or myotomy, but is more common near the gastroesophageal junction or distally in the cardia. Our data show similar episodes of minor bleeding in both study arms. There were no episodes of delayed bleeding in our study. According to some authors, vascularity is less along the posterior aspect [24]. However, the clinical relevance of that same remains to be proven.

Mucosal perforation is a complication that occurs in around $6 \%$ of POEM procedures with a range of $0 \%$ to $25 \%$ of cases [4]. In current study, incidence of mucosal perforation was higher with in the anterior group $(20 \%)$ than in the posterior group (3.33\%; $P=0.03)$. All the mucosal perforations were detected intraprocedurally and were successfully closed with clips. No leak or infection resulted and patients had similar postoperative courses. The anterior approach requires steeper angulation of the scope tip, resulting in greater fling of the knife during myotomy. Therefore, the mucosa at the opposite end may very well be injured due to inadvertent sudden flinging of the knife [18].

Treatment of AC is mostly palliative and involves a balance between relief of dysphagia and occurrence of acid reflux. GERD is a known complication irrespective of the treatment used. In LHM there is alteration of the natural antireflux barrier including phrenoesophageal membrane while in POEM these intra-abdominal esophageal anatomic structures are preserved. Reflux rates for LHM with partial fundoplication are comparable to that for POEM. It is important to minimize reflux after POEM, as there is no concurrent endoscopic antireflux procedure performed with the procedure. In this study, we observed a significant difference in incidence of GERD with different routes of myotomy. Esophageal acid exposure time was significantly higher in the posterior group $(13.99 \pm 14.48$ vs $2.98 \pm$ 4.24; $P<0.01)$. Moreover, significantly more patients in that group had elevated DeMeester scores. In contrast, there was no difference in symptomatic and endoscopic GERD (esophagitis) between the 2 groups. Posterior myotomy may cause more
GERD as it involves cutting of both clasp and sling fibers at the GE junction [24]. However, that needs to be further proven by larger multicenter trials before any recommendation can be made.

The strength of the current study is that this is the first randomized pilot study comparing anterior and posterior POEM. It is a single-center study so other confounding factors are minimal and all the operators had completed their learning curve for both approaches to myotomy. GERD was documented objectively with 24-hour $\mathrm{pH}$ studies, in addition to symptom assessment and EGD. However, the noteworthy limitation is that this pilot study had a short follow-up period and the results, although significant, should not be considered as definitive. The approaches for myotomy should be evaluated further in larger, multicenter studies with longer follow-up.

\section{KEY MESSAGES}

- Randomized pilot study comparing outcomes of anterior versus posterior myotomy for POEM

- Both approaches had comparable total operative time

- Less time and fewer clips were required for mucosostomy closure in the posterior group

- Incidence of mucosal injuries was higher during anterior myotomy, although all such injuries were detected and closed during the procedure with no sequelae

- Total postoperative acid exposure and mean DeMeester score were greater in the posterior myotomy group

- Increased acid exposure did not translate into clinically or endoscopically significant GERD

\section{Conclusion}

In conclusion anterior and posterior approaches to POEM seem to have similar operative times and efficacy but a recommendation for the preferred approach to myotomy is difficult to make based on just this study. Given the increased probability of GERD with the posterior approach, further studies that include larger numbers of patients are warranted to confirm this finding.

\section{Competing interests}

None

\section{References}

[1] Rohof WO, Salvador R, Annese V et al. Outcomes of treatment for achalasia depend on manometric subtype. Gastroenterology 2013; 144: 718 - 725; quiz e13-4

[2] Hungness ES, Teitelbaum EN, Santos BF et al. Comparison of perioperative outcomes between peroral esophageal myotomy (POEM) and laparoscopic Heller myotomy. J Gastrointest Surg 2013; 17: 228 235 
[3] Inoue H, Sato H, Ikeda H et al. Per-Oral Endoscopic Myotomy: A Series of 500 Patients. J Am Coll Surg 2015; 221: 256-264

[4] Stavropoulos SN, Modayil RJ, Friedel D et al. The International Per Oral Endoscopic Myotomy Survey (IPOEMS): a snapshot of the global POEM experience. Surg Endosc 2013; 27: 3322 - 3338

[5] Ramchandani M, Nageshwar ReddyD. Peroral endoscopic myotomy: technique of mucosal incision. Clin Gastroenterol Hepatol 2014; 12: 900-901

[6] Ramchandani M, Nageshwar ReddyD, Darisetty S et al. Peroral endoscopic myotomy for achalasia cardia: Treatment analysis and follow up of over 200 consecutive patients at a single center. Dig Endosc 2016; 28: 19-26

[7] Neyaz Z, Gupta M, Ghoshal UC. How to perform and interpret timed barium esophagogram. J Neurogastroenterol Motil 2013; 19: 251 256

[8] Kahrilas P], Bredenoord AJ, Fox M et al. The Chicago Classification of esophageal motility disorders, v3. 0. Neurogastroenterol Motil 2015; 27: $160-174$

[9] Kusano M, Shimoyama Y, Sugimoto $S$ et al. Development and evaluation of FSSG: frequency scale for the symptoms of GERD. J Gastroenterol 2004; 39: 888-891

[10] Kim GH. How to Interpret Ambulatory 24 hr Esophageal pH Monitoring. J Neurogastroenterol Motil 2010; 16: $207-210$

[11] Moonen A, Annese V, Belmans A et al. Long-term results of the European achalasia trial: a multicentre randomised controlled trial comparing pneumatic dilation versus laparoscopic Heller myotomy. Gut 2016; 65: $732-739$

[12] Yaghoobi M, Mayrand S, Martel M et al. Laparoscopic Heller's myotomy versus pneumatic dilation in the treatment of idiopathic achalasia: a meta-analysis of randomized, controlled trials. Gastrointest Endosc 2013; 78: $468-475$

[13] Ujiki MB, Yetasook AK, Zapf M et al. Peroral endoscopic myotomy: A short-term comparison with the standard laparoscopic approach. Surgery 2013; 154: 893-897; discussion 897-900
[14] Bhayani NH, Kurian AA, Dunst CM et al. A comparative study on comprehensive, objective outcomes of laparoscopic Heller myotomy with per-oral endoscopic myotomy (POEM) for achalasia. Ann Surg 2014; 259: $1098-1103$

[15] Inoue H, Minami H, Kobayashi Y et al. Peroral endoscopic myotomy (POEM) for esophageal achalasia. Endoscopy 2010; 42: 265-271

[16] Philips GM, Dacha S, Keilin SA et al. Concurrent myotomy and tunneling after establishment of a half tunnel instead of myotomy after establishment of a full tunnel: a more efficient method of peroral endoscopic myotomy. Endosc Int Open 2016; 4: E403-408

[17] Teitelbaum EN, Sternbach JM, El KhouryR et al. The effect of incremental distal gastric myotomy lengths on EG) distensibility during POEM for achalasia. Surg Endosc 2016; 30: 745 - 750

[18] Bechara R, Onimaru M, Ikeda H et al. Per-oral endoscopic myotomy, 1000 cases later: pearls, pitfalls, and practical considerations. Gastrointest Endosc 2016; 84: $330-338$

[19] Kurian AA, Dunst CM, Sharata A et al. Peroral endoscopic esophageal myotomy: defining the learning curve. Gastrointest Endosc 2013; 77 : $719-725$

[20] Stavropoulos SN MR, Brathwaite C, Halwan B et al. Anterior vs Posterior PerOral Endoscopic Myotomy (POEM): Is There a Difference in Outcomes? Gastrointest Endosc 2016; 83: AB145

[21] Zhang XC, Li QL, Xu MD et al. Major perioperative adverse events of peroral endoscopic myotomy: a systematic 5-year analysis. Endoscopy 2016; 48: $967-978$

[22] Werner YB, von Renteln D, Noder T et al. Early adverse events of peroral endoscopic myotomy. Gastrointest Endosc 2017; 85: 708-718. e2

[23] Khashab MA, El ZeinM, Kumbhari V et al. Comprehensive analysis of efficacy and safety of peroral endoscopic myotomy performed by a gastroenterologist in the endoscopy unit: a single-center experience. Gastrointest Endosc 2016; 83: 117-125

[24] Grimes KL, Inoue H. Per oral endoscopic myotomy for achalasia: A detailed description of the technique and review of the literature. Thorac Surg Clin 2016; 26: 147-162 